\title{
Peertechz
}

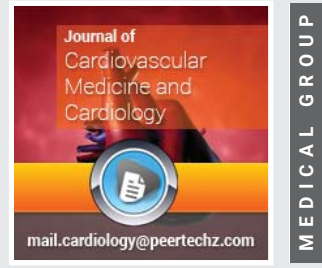

\section{Cardiovascular risk factors and clinical pattern in young Nepalese population with acute coronary syndrome presenting to a tertiary care center of Nepal}

\author{
Ravi Sahi ${ }^{1 *}$, Rajesh Shah², Ratna Mani Gajurel', Raja Ram \\ Khanal' ${ }^{1}$, Chandra Mani Poudel', Surya Pathak' ${ }^{1}$ and Vijay \\ Yadav $^{1}$
}

${ }^{1}$ Department of Cardiology, Manmohan Cardio Thoracic Vascular and Transplant Centre (MCVTC); Institute of Medicine, TUTH, Nepal

2Department of Medicine, AMDA Hospital, Damak, Nepal

Received: 31 July, 2020

Accepted: 06 August, 2020

Published: 07 August, 2020

*Corresponding author: Dr. Ravi Sahi, Department of Cardiology, Manmohan Cardio Thoracic Vascular and Transplant Centre (MCVTC), Institute of Medicine, TUTH, Nepal, Tel: +977 9841759273; E-mail: drravisahi@gmail.com; drravisahi@yahoo.com

ORCID: https://orcid.org/0000-0001-5305-7316

Keywords: Acute coronary syndrome; Coronary angiogram; Young adult

https://www.peertechz.com

Check for updates

\begin{abstract}
Background and objectives: Cardiovascular disease is a major health problem reaching epidemic proportions. Although Acute Coronary Syndrome (ACS) is an uncommon entity in the young, it constitutes a rising burden in the socioeconomic status of the country because of its impact on the economically productive age group. Early identification and control of the cardiovascular risk factors helps to prevent cases of Myocardial Infarction (MI) in young resulting in reduced health burden. Therefore, we aimed to assess clinical pattern and the prevalence of cardiovascular risk factors in the young and economically productive population of an underdeveloped country to lower the socioeconomic burden.
\end{abstract}

Methods: A total of 60 patients presenting at the cardiology department of Manmohan Cardiothoracic Vascular and Transplant Center were included in our study after fulfilling the inclusion criteria. ACS was diagnosed by cardiac enzymes, electrocardiography, and echocardiography and coronary intervention was done in the cardiac catheterization room. Patients were followed up at 1 and 3-months and reassessed clinically and by echocardiography.

Results: Mean age of presentation was $38.55+4.98(\mathrm{SD})$ years. Over three-fourth of the patients were male (80\%) and nearly three-quarter experienced ST-elevated MI (73\%). Smoking was the most prevalent risk factor (67\%), followed by dyslipidemia (40\%), diabetes (32\%), hypertension (30\%), and obesity (13\%). Most of the patients presented with single-vessel disease (65\%), followed by double-vessel disease (18\%), triple-vessel disease (12\%), left main disease (3\%), and minor coronary artery disease $(2 \%)$.

Conclusions: ACS in underdeveloped country is more common in male and single-vessel disease is the most common clinical pattern of ACS and smoking the most prevalent risk factor.

\section{Introduction}

Cardiovascular disease is a major health problem reaching epidemic proportions. The Global Burden of Disease (GBD) study done in 2010 reported that Coronary Artery Disease
(CAD) deaths have drastically increased in South Asia by $87 \%$ between 1990 to 2010 second only to East Asia which has been predicted to increase a further $50 \%$ by $2030[1-3]$. Coronary Heart Disease (CHD) related deaths in Nepal reached 34,167 ( $21 \%$ of total deaths) according to 2018 WHO published data, 
positioning Nepal at $38^{\text {th }}$ position as per the Age-Standardized Death Rate (184.95 per 100,000 population) [4].

Although Acute Coronary Syndrome (ACS) is an uncommon entity in the young, 5-10\% of Myocardial Infarctions (MI) occur in patients $<45$ years old [5-7]. The occurrence of ACS in young constitutes an important problem for the patients and their treating physicians because of its devasting effect on their more active lifestyle. This also leads to early morbidity and mortality in what should be the most productive years of life. Previous studies have found a high prevalence of smoking, obesity, hyperlipidemia, and a positive family history among young MI patients [5-8].

Most of the existing studies on young ACS patients are from the developed nations and presently there is no contemporary data on the prevalence, risk factors and clinical patterns of such patients in the underdeveloped countries. The young population constitutes the economically active age-group which in turn significantly influences the country's economy, especially in underdeveloped countries. Population of the 1645 years age group is considered as the youth population in Nepal as per the Ministry of Youth and Sports. The aim of this study was to assess the prevalence, risk-factors, and clinical patterns in ACS patients $<45$ years of age from Nepal.

\section{Methods}

This study which was carried out at Manmohan Cardiothoracic Vascular and Transplant Center (MCVTC), a tertiary referral hospital in Nepal, from $1^{\text {st }}$ May 2018 to $30^{\text {th }}$ April 2019. Sixty patients who presented to Cardiology Department of MCVTC in the above time period with first episode of ACS or were undergoing coronary angiography, were studied. All the patients provided written informed consent at study entry. The study was approved by Institutional review board. The following pre-specified inclusion and exclusion criteria were applied:

\section{Inclusion criteria}

- Patient aged <45 years with ACS presenting at Emergency or Outpatient department.

\section{Exclusion criteria}

- Patient's aged $\geq 45$ years.

- Patient previously diagnosed with ACS.

- Patient with previous history of percutaneous transluminal angioplasty (PTCA) and (coronary artery bypass graft) CABG surgery.

- Patient who did not give written consent for the study.

Dyslipidemia \& premature CAD was defined as per ATP III guideline [9], HTN as per JNC 7 guideline [10], diabetes as per ADA guideline [11] and obesity as per Asia Pacific guidelines [12]. Normal vessels were defined as the complete absence of any disease in the Left Main Coronary Artery (LMCA), Left Anterior Descending Artery (LAD), Right Coronary Artery (RCA) and Left
Circumflex Artery (LCX) while significant CAD was defined as a diameter stenosis $>50 \%$ in each major epicardial artery.

\section{Statistical analysis}

The results are reported as mean (SD) for the quantitative variables and number (\%) for the categorical variables. The groups were compared using the Student's t-test for the continuous variables and the Chi-square test for the dichotomous variables. P-value $<0.05$ were considered as statistically significant. All the statistical analyses were carried out via Statistical Package for Social Sciences version 20 (SPSS, IL, Chicago Inc., USA).

\section{Results}

The study included total of 60 young ACS patients, among which majority were male $48(80 \%)$ and $12(20 \%)$ were female. The mean age of presentation was 38.55 (4.98) years. Mean age of male and female patients were 38.08 (5.06) and 40.42 (4.31) years respectively. $46 \%$ of patients were around 41-44 years of age and $2 \%$ were around 21-25 years of age. Most common presentation in ACS was ST elevated myocardial infarction (STEMI) in $44(73 \%)$ patients followed by nonST elevated myocardial infarction (NSTEMI) in 10 (17\%) and unstable angina (UA) in $6(10 \%)$. Baseline characteristics are mentioned in Table I.

\begin{tabular}{|c|c|c|}
\hline Table I: Baseline characteristics of the study population $(\mathrm{N}=60)$ \\
\hline & Mean & Std. Deviation \\
\hline Age (years) & 38.55 & 4.98 \\
\hline Fasting blood sugar $(\mathrm{mg} / \mathrm{dl})$ & 129.2 & 44.95 \\
\hline HbA1C & 5.9 & 1.41 \\
\hline Creatinine(mg/dl) & 0.83 & 0.17 \\
\hline Triglyceride & 152.4 & 93.8 \\
\hline Total cholesterol & 158.43 & 40.69 \\
\hline HDL & 35.0 & 7.87 \\
\hline LDL & 106.5 & 34.0 \\
\hline
\end{tabular}

\section{Risk factors analysis}

A total of $19(32 \%)$ patients were diabetic and 18 (30\%) patients were hypertensive. Smoking was the most prevalent risk factor found in $40(67 \%)$ patients. Dyslipidemia was present in $24(40 \%)$ patients. Family history of premature CAD was present in $4(7 \%)$ of patients. Three $(5 \%)$ patients had hypercoaguable state in which 1 had protein S deficiency, 1 had protein S \& C deficiency, and 1 had protein S deficiency along with hyperhomocystenemia. One $(2 \%)$ patient had coronary artery anomaly i.e. ectasia of proximal LAD. One (2\%) had rheumatoid arthritis and $1(2 \%)$ patient had HIV infection and was taking Anti-Retroviral Therapy (ART) (Table II).

Smoking was significantly higher in male population $(75 \%)$ compared to female $(33 \%)(\mathrm{p}=0.006)$. Of all the patients that smoked, $9(23 \%)$ had history of smoking $>10$ packs per year. Dyslipidemia was seen higher in male population $42 \%$ 
compared to female $33 \%$. Eight patients fulfilled the criteria for obesity as per Asia-Pacific guidelines. There was no significant gender difference in prevalence of dyslipidemia, hypertension, premature CAD \& diabetes (Table III).

Table II: Distribution of study population according to clinical risk factors.

\begin{tabular}{|c|c|c|}
\hline Clinical Risk factors & Frequency & Percent (\%) \\
\hline Smoking & 40 & 66.7 \\
\hline Diabetes Mellitus & 19 & 31.7 \\
\hline Hypertension & 18 & 30 \\
\hline Dyslipidemia & 24 & 40 \\
\hline Family h/o Premature CAD & 4 & 6.7 \\
\hline Obesity & 8 & 13.3 \\
\hline Hypercoaguable state & 3 & 5 \\
\hline Coronary artery anomaly & 1 & 1.6 \\
\hline Connective tissue disorder & 1 & 1.6 \\
\hline HIV patient & 1 & 1.6 \\
\hline
\end{tabular}

Table III: Comparison between males and females with risk factors.

\begin{tabular}{|c|c|c|c|}
\hline Risk factors & Male & Female & p-value \\
\hline Smoking & 36 & 4 & $\mathbf{0 . 0 0 6}$ \\
\hline Dyslipidemia & 20 & 4 & 0.59 \\
\hline Diabetes & 15 & 4 & 0.89 \\
\hline Hypertension & 13 & 5 & 0.32 \\
\hline Premature CAD & 4 & 0 & 0.30 \\
\hline
\end{tabular}

\section{Electrocardiography findings}

In this study anterior wall electrocardiogram (ECG) changes (45\%) was the most common ECG finding in patients with acute STEMI, followed by inferior wall (28\%). Approximately one-third of patients had others changes like ST depression or normal ECG.

\section{Echocardiographic profile}

During admission, assessment of left ventricle systolic function was done by echocardiography of which 19 (32\%) had normal ejection fraction, $16(27 \%)$ had mild left ventricular systolic dysfunction, $23(38 \%)$ had moderate left ventricular systolic dysfunction and $2(3 \%)$ had severe left ventricular systolic dysfunction (Figure 1).

\section{Angiographic profile}

Out of 60 patients, single vessel disease (SVD) was seen in $39(65 \%)$, double vessel disease (DVD) in $11(18 \%)$, triple vessel disease (TVD) in $7(12 \%)$, left main disease in $2(3 \%)$, and minor lesion was seen in 1 ( $2 \%$ ) (Figure 2$)$.

In STEMI, SVD was seen in $32(72 \%)$, DVD in $8(18 \%)$, TVD in $2(5 \%)$, and Left Main disease in $2(5 \%)$. In NSTEMI, SVD was seen in $5(50 \%)$, DVD in $2(20 \%)$, TVD in $2(20 \%)$ and minor lesion in $1(10 \%)$. In UA, SVD was seen in $2(33 \%)$, DVD in $1(17 \%)$ and TVD in $3(50 \%)$ (Figure 3$)$.

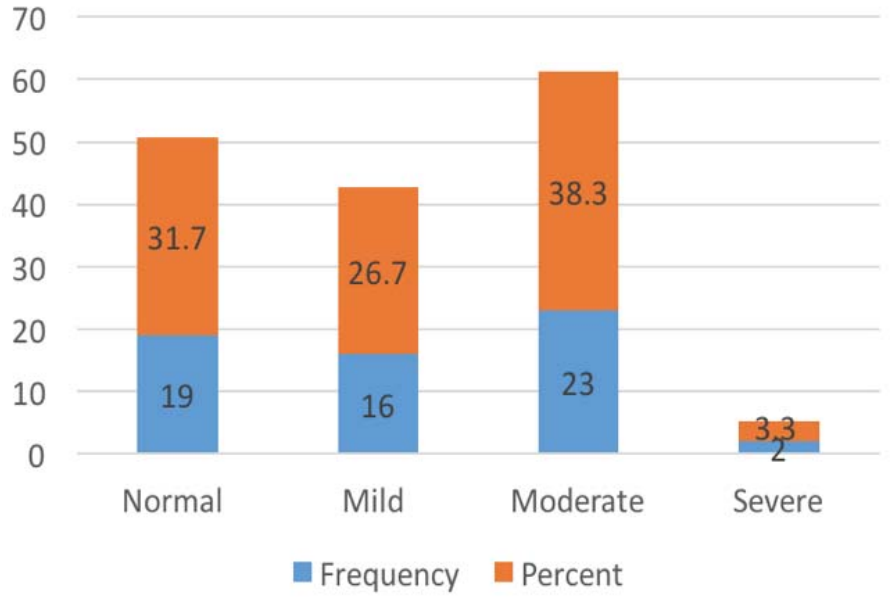

Figure 1: During admission patterns of LV systolic function.

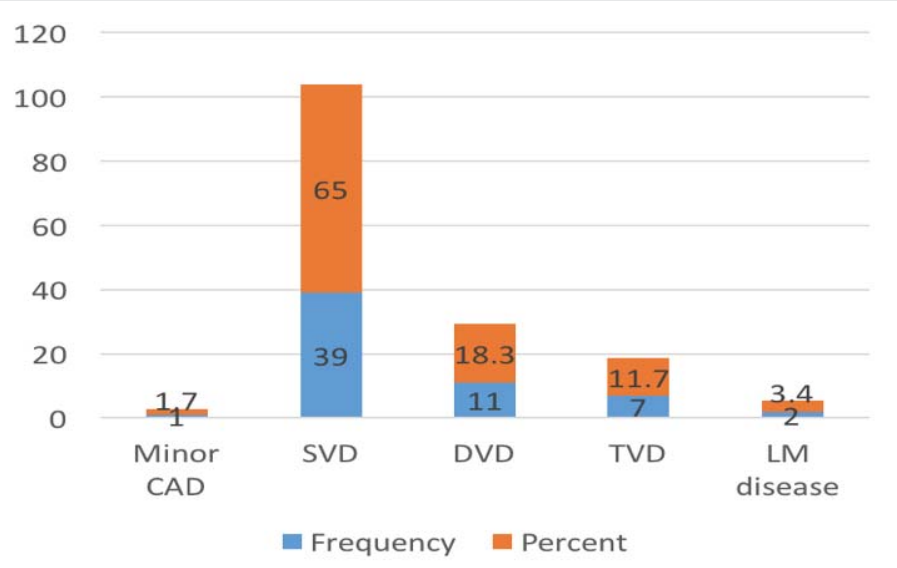

Figure 2: Distribution of study population according to CAG findings.

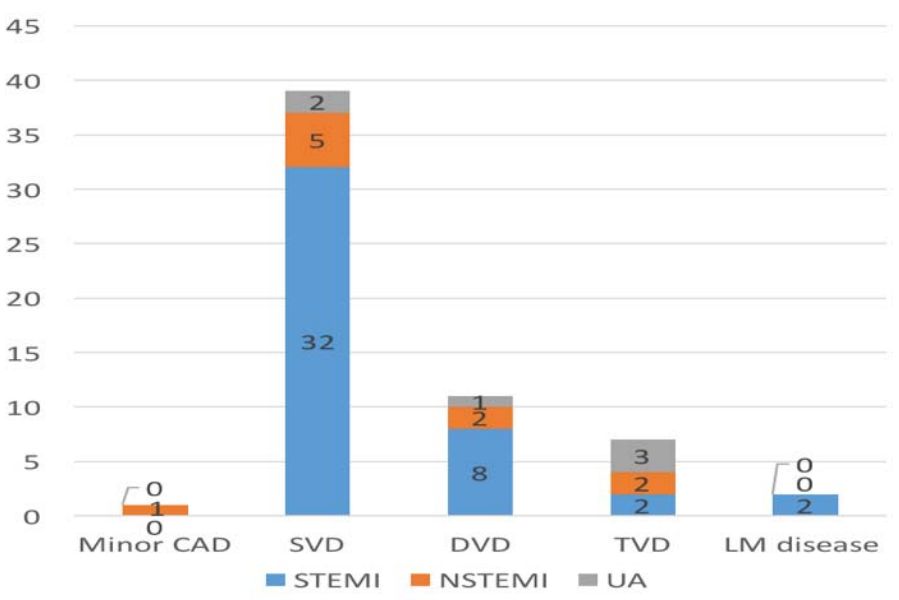

Figure 3: Distribution of study population according to extent of disease.

Of 48 male patients, 35 (73\%) were STEMI, 9 (19\%) were NSTEMI and 4 (8\%) were UA. Whereas in 12 female patients 9 $(75 \%)$ were STEMI, 1 ( $8 \%)$ NSTEMI and $2(17 \%)$ were UA. There was no gender difference in the presentation of ACS and in the number of vessels involved.

Of all the risk factors, diabetes was significantly associated 
with multi vessel lesion compared to non-multivessel lesion (53\% vs 24\%; $p=0.03$ ) (Table IV).

On analyzing culprit artery, LAD was found to be the most commonly involved $(60 \%)$ followed by RCA $(23 \%)$ and LCX $(17 \%)$.

\section{Treatment modalities used in ACS patients}

Figure 4: Out of total 44 STEMI patients, of which 36 patients presented within window period and underwent primary intervention. Among those 36 patients, stents were deployed in 32 while POBA was done in 4 . In these 4 patients who had undergone POBA 1 was later referred to cardiac surgery for CABG while other 3 were managed medically. Other 8 STEMI patients presented beyond window period of which 5 underwent routine PCI, 2 patients were referred to cardiac surgery for $\mathrm{CABG}$ and 1 was was managed medically. Remaining 16 patients of NSTEMI \& UA beside 1 all underwent routine PCI during hospital admission.

\section{Complications}

$8 \%$ patients developed cardiogenic shock requiring inotropes, while $3 \%$ developed venous thromboembolism of which 1 patient underwent emergency embolectomy, 5\% developed heart failure which was managed with diuretics and inotropes, $2 \%$ had complete heart block requiring temporary and then permanent pacemaker insertion, $2 \%$ had significant arrhythmia, $2 \%$ developed CIN, $7 \%$ developed acute pericarditis which was managed with high dose aspirin and colchicine. There was two mortality ( $3 \%$ ) during hospital admission, both of them were female, diagnosed as extensive anterior wall MI in cardiogenic shock (Figure 5).

\section{Follow up}

During 1 month follow 23 (38\%) had Normal left ventricular ejection fraction (LVEF), $12(20 \%)$ had mild left ventricular systolic dysfunction (LVSD), 19 (32\%) had Moderate LVSD, $1(2 \%)$ had severe LVSD and $5(8 \%)$ patients were lost to follow up. During 3 months follow up 27 (45\%) had Normal LVEF, 16 (28\%) had Mild LVSD, 9 (15\%) had Moderate LVSD \& 1 (2\%) had severe LVSD. Further 2 patients were lost to follow up making a total of $7(12 \%)$ (Figure 6$)$.

\section{Re-admission}

Two patients were readmitted within 3 months duration of which 1 was a case of inferior wall MI with right ventricular extension with moderate LVSD and right ventricular dysfunction, who presented due to Acute Decompensated Heart Failure (ADHF) and was managed with inotropes and diuretics; and the other one was the case of extensive anterior wall MI with HIV undergoing ART, who presented because of late stent thrombosis and was managed by Plain Old Balloon Angioplasty (POBA).

\section{Discussion}

This is an observational prospective study of 60 patients aged 44 and below admitted with a diagnosis of ACS at the
Table IV: Comparison between multivessel and non multivessel lesion with risk factors.

\begin{tabular}{|c|c|c|c|}
\hline Risk factors & Multivessel & Non multivessel & p-value \\
\hline Smoking & 14 & 26 & 0.69 \\
\hline Dyslipidemia & 10 & 14 & 0.26 \\
\hline Diabetes & 10 & 9 & 0.03 \\
\hline Hypertension & 9 & 9 & 0.07 \\
\hline Premature CAD & 2 & 2 & 0.46 \\
\hline
\end{tabular}

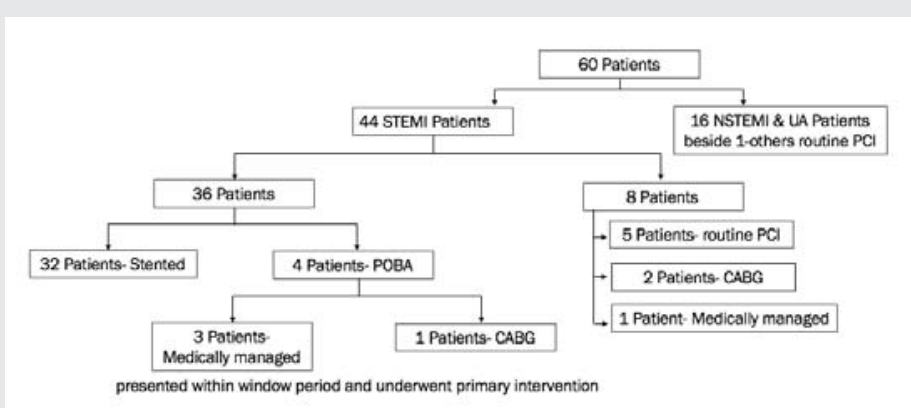

Figure 4: Treatment modalities in young ACS patients.

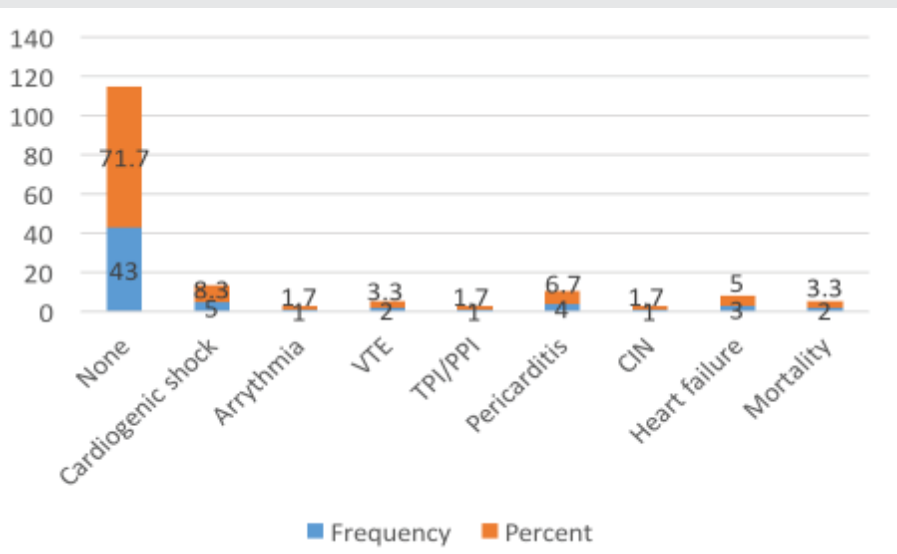

Figure 5: In hospital complications of ACS.

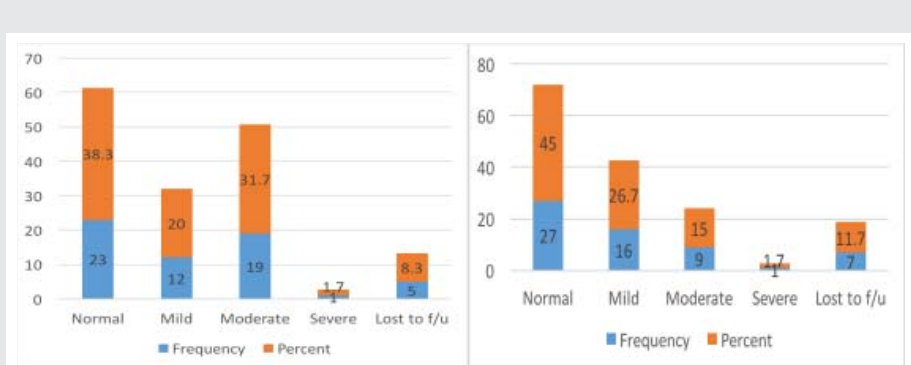

Figure 6: Follow up echocardiography profile in duration of $1 \& 3$ months.

Department of Cardiology, MCVTC. The mean age of patients presenting with ACS was $38.55+4.98$ with male predominance which was similar to the study conducted by E. Incalcaterra [13]. In young ACS patients the most common risk factor was found to be smoking (66\%) with male predominance $(75 \%)$ which was also similar in the study done by Zimmerman, et al. where $73 \%$ had a history of smoking [13]. Haque, et al. also stated that smoking was most common risk factor (64\%) with male preponderance (77\%) [14]. So, there's no doubt that either in old or young smoking is hazardous to health. 
The other risk factors besides smoking are diet rich in cholesterol, sedentary lifestyle, diabetes, hypertension, and paternal history of cardiovascular disease [15,16]. This illustrates the need to increase awareness among the young population and evaluate the risk factors among those with family history or those at high-risk. These simple measures can make a large difference in preventing the occurrence of MI in young.

In $40 \%$ of young ACS patients dyslipidemia was present which was comparable to other existing studies which showed a similar prevalence of $47 \%$ (Moccetti and Malacrida, et al. 1997), 42\% (Dwiwedi, et al. 2000), and 42\% (Dani, et al. 2003) [17-19].

Another risk factor, obesity was present in $13 \%$ of our cases which is similar to reported by Siwach, et al. (14\%) and Singh, et al. $(16 \%)[20,21]$. The disproportionate rise in the prevalence of heart disease among certain ethnic groups like people of Asian Indian origin has become a study of great interest. These people in very young age tends to get ACS and more complex coronary artery abnormalities probably due to proliferation of vascular endothelial cells and activation of inflammatory response promoting with endothelial dysfunction and atherosclerosis [22-25].

Diabetes and hypertension were also found to be higher (32\% and $30 \%$ respectively) in younger generation of our population and diabetes was significantly associated with multivessel disease. In the study done by Paudel, et al. $45 \%$ were hypertensive with $14 \%$ diabetic and diabetes was associated with multivessel disease and poor prognosis [26]. Many other studies have reported hypertension in $30-50 \%$ and diabetes in $20-30 \%$ of individuals with young ACS [27-32].

The family history of CAD is associated with increased risk of young ACS and strengthened the belief of important risk factor for CAD. In patients with positive family history it had been reported that risk of developing ACS was more than a decade earlier compared to those without a family history of CAD [33]. In our study, $7 \%$ of the young ACS presented with a positive family history of CAD. There are many genomic studies suggesting different chromosomal abnormalities contributing to the onset of ACS in young [34].

Apart from the classical risk factors for CAD, young patients are likely to have other risk factors like coagulation abnormalities (thrombophilia, Protein $\mathrm{C}$ and S deficiency) and vasculitis. In our study only 3 patients $(5 \%)$ had hypercoaguable state and $1(2 \%)$ had connective tissue disorder whereas in the study conducted in Nepal by Laudari, et al. 5 patients (13\%) were found to have coagulation abnormalities [35].

Angiographic pattern has been analyzed in different studies and in our study, SVD was the most common angiographic finding (65\%), while LAD was the most common infarctrelated artery (60\%). In a study done by Tambyah, et al. on MI in young, all patients had evidence of atherosclerotic disease, majority had single vessel disease and LAD was the most common infarct related artery [36]. Similarly, in the study of
Colkesen, et al. involving young STEMI patients it was found that LAD was the most common vessel involved followed by RCA and LCX [37].

In our study anterior wall STEMI was about $45 \%$ followed by $28 \%$ inferior wall STEMI, and $27 \%$ of patients had no ECG changes. Alappat, et al. (56\% anterior wall ,38\% inferior wall and $6 \%$ others) and Tambyah, et al. both studies demonstrated that anterior wall MI (AWMI) was the most common STEMI in young patients $[36,38]$.

AWMI with severe LV systolic dysfunction was the antecedent cause of death in $3 \%$ in our study during admission period. Stone, et al. quoted that young patients with anterior infarction had a substantially worse in-hospital and followup clinical course evidenced by a larger infarct size , higher incidence of heart failure, LV dysfunction and ventricular arrhythmia [38].

The prognosis of young ACS depends not only on diagnosing early and treating adequately but also on identifying, preventing and treating the risk factors at primary and secondary level Heart failure is a most common and serious complication after MI which was found in $14 \%, 18 \%$, and $9 \%$ in the series of Sarr, et al. Al-Khadra, et al. and Kanitz, et al. respectively [40-42]. However, in our study only $5 \%$ had heart failure. A relationship between age and heart failure has been reported by Magid et al with a greater frequency of occurrence in the elderly compared to young subjects [43].

\section{Limitations}

This study has effectively highlighted the clinical profile of young MI patients, but there were few limitations. It was conducted in a single center, which may not be representative of whole population. As no control group was used, the risk of each factor could not be analyzed statistically. Larger studies involving multiple centers are required focusing on the risk factors and management of young MI.

\section{Conclusion}

From this study we observed that CAD is a major health challenge. Young patients diagnosed with ACS have some important differences that should be appreciated. The most important modifiable risk factor is smoking and dyslipidemia. In our study population, there was male preponderance. STEMI was the most common presentation of ACS. Single vessel disease was the most common CAG finding irrespective of type of ACS and LAD was found to be most commonly involved artery. Diabetic patients had more multivessel CAD compared to non-diabetics.

A careful search for other contributing risk factors is necessary as progressive atherosclerosis may not always be the underlying pathophysiology. If timely managed, young patients with AMI have promising inhospital prognosis. In order to decrease long-term morbidity and mortality from $\mathrm{CAD}$, young patients should be concerned on preventive measures like knowledge about risk factors, physical exercise and healthy diet. 


\section{Acknowledgement}

We would like to specially thanks to Dr Hemant Shrestha,Dr Sanjeev Thapa ,Dr Shovit Thapa and Dr Surya Devkota.

\section{References}

1. Mathers $C D$, Loncar D (2006) Projections of global mortality and burden of disease from 2002 to 2030. PLos Med 3: e442. Link: https://bit.ly/3idEMLF

2. Joshi P, Islam S, Pais P, Reddy S (2007) Risk factors for early myocardial infarction in South Asians compared with individuals in other countries. JAMA 297: 286-294. Link: https://bit.ly/3iavika

3. Yusuf S, Reddy S, Ôunpuu S, Anand S (2001) Global burden of cardiovascular diseases part I: general considerations, the epidemiologic transition, risk factors, and impact of urbanization. Circulation 104: 2746-2753. Link: https://bit.ly/30A1gjV

4. World Health Rankings 2018. World Health Organization. Link: https://bit.ly/2DISzLO

5. Doughty M, Mehta R, Bruckman D, Das S, Karavite D, et al. (2002) Acute myocardial infarction in the young - the University of Michigan experience. Am Heart J 143: 56-62. Link: https://bit.ly/2XF3Ymu

6. Choudhury L, Marsh JD (1999) Myocardial infarction in young patients. Am J Med 107: 254-261. Link: https://bit.ly/33BZmBo

7. Zimmerman FH, Cameron A, Fisher LD (1995) Myocardial infarction in young adults: angiographic characterization, risk factors and prognosis. (Coronary Artery Surgery Registry). J Am Col Cardiol 26: 654-661. Link: https://bit.ly/3flZUrD

8. Avezum A, Makdisse M, Spencer F, Gore JM, Fox KA, et al. (2005) Impact of age on management and outcome of acute coronary syndrome: observations from the Global Registry of Acute Coronary Events (GRACE). Am Heart J 149: 67-73. Link: https://bit.ly/3fAoydU

9. Feeman WE (2001) Executive Summary of The Third Report of The National Cholesterol Education Program (NCEP) Expert Panel on Detection, Evaluation, and Treatment of High Blood Cholesterol in Adults (Adult Treatment Panel III). Expert Panel of Detection, Evaluation, and Treatment of High Blood Cholestero in Adults. Journal of the American Medical Association. 285: 2486-2497. Link: https://bit.ly/31GQV5h

10. Chobanian AV, Bakris GL, Black HR, Cushman WC, et al. (2003) The seventh report of the joint national committee on prevention, detection, evaluation, and treatment of high blood pressure: the JNC 7 report. JAMA 289: 2560-2571. Link: https://bit.ly/30BLyEZ

11. American Diabetes Association (2018) 2. Classification and diagnosis of diabetes: standards of medical care in diabetes-2018. Diabetes care 41: S13 S27. Link: https://bit.ly/30AVS04

12. WHO/IASO/IOTF (2000) The Asia-Pacific perspective: redefining obesity and its treatment. Health Communications Australia; Melbourne. Link: https://bit.ly/3igmCc 1

13. Incalcaterra E, Caruso M, Lo Presti R, Caimi G (2013) Myocardial infarction in young adults: risk factors, clinical characteristics and prognosis according to our experience Clin Ter 164: e77-e82. Link: https://bit.ly/33Bwbyo

14. Haque AF, Siddiqui AR, Rahman SM, Iqbal SA, Fatema NN, et al. (2010) Acute coronary syndrome in the young-risk factors and angiographic pattern. Cardiovascular Journal 2: 175-178. Link: https://bit.ly/3keYoAV

15. Ismail J, Jafar TH, Jafary FH, White F, Faruqui AM, et al. (2004) Risk factors for non-fatal myocardial infarction in young South Asian adults. Heart 90: 259263. Link: https://bit.ly/30A28Fd

16. Egred M, Vishwanath G, Davis GK (2005) Myocardial infarction in young adults.
Postgrad Med J 81: 741-745. Link: https://bit.ly/30A29ZN

17. Moccetti T, Malacrida R, Pasotti E, Sessa F, Genoni M, et al. (1997) Epidemiologic Variables and Outcome of 1972 Young Patients with Acute Myocardial Infarction: Data from the GISSI-2 Database. Arch Intern Med 157 865-869. Link: https://bit.ly/3a3AOII

18. Dwiwedi S, Dwiwedi G, Sharma S (2000) Coronary artery disease in young: Heredofemilial or Faculty Life Style or both. JIACM 1: 245-251.

19. Dani SI, Ghosh SB, Prajapati JS, Jain S (2003) Clinical and coronary Angiographic profile of Coronary Artery Disease in a young Gujarati population. $\mathrm{IHJ}$.

20. Jit Singh P (2001) Myocardial infarction in young- A Study of 42 cases. JAP 49: 32

21. Siwach SB, Singh H, Sharma D, Katyal VK (1998) Profile of young Acute Myocardial Infarction in Haryana. JAPI 46: 424-426. Link: https://bit.ly/31txwoc

22. Enas EA, Mehta JL (1995) Malignant coronary artery disease in young Asian Indians: thoughts on pathogenesis, prevention and treatment. Clin Cardiol 18 131-135. Link: https://bit.ly/31GSosj

23. Herrmann SM, Ricard S, Nicaud V, Mallet C, Arveiler D, et al. (1998) Polymorphisms of the tumour necrosis factor-alpha gene, coronary heart disease and obesity. Eur J Clin Invest 28: 59-66. Link: https://bit.ly/2C9xZ6k

24. Yudkin JS, Stehouwer CD, Emeis JJ, Coppack SW (1999) C-reactive protein in healthy subjects: associations with obesity, insulin resistance, and endothelial dysfunction: a potential role for cytokines originating from adipose tissue? Arterioscler thromb vasc biol 19: 972-978. Link: https://bit.ly/3gC7q80

25. Alexander JK (2001) Obesity and coronary heart disease. Am J Med Sci 321 215-224. Link: https://bit.ly/3aaWtc0

26. Paudel N, Alurkar VM, Jha GS, Kafle R, et al. (2018) Profile of Acute Coronary Syndrome In Young People: A Hospital Based Observational Study in Western Nepal. BJHS 3: 361-365. Link: https://bit.ly/3fyMzSA

27. Yagi H, Komukai K, Hashimoto K, Kawai M, Ogawa T, et al. (2010) Difference in risk factors between acute coronary syndrome and stable angina pectoris in the Japanese: Smoking as a crucial risk factor of acute coronary syndrome. $J$ Cardiol 55: 345-353. Link: https://bit.ly/30yfCBi

28. Gotto AM (1986) Interac ons of the major risk factors for coronary heart disease. Am J Med 80: 48-55.

29. Hirsch AT, Haskal ZJ, Hertzer NR, Bakal CW, Creager MA, et al. (2006) ACC/ AHA 2005 practice guidelines for the management of patients with peripheral arterial disease (lower extremity, renal, mesenteric, and abdominal aortic) a collaborative report from the American Association for Vascular Surgery/ Society for Vascular Surgery,* Society for Cardiovascular Angiography and Interventions, Society for Vascular Medicine and Biology, Society of Interventional Radiology, and the ACC/AHA Task Force on Practice Guidelines (writing committee to develop guidelines for the management. Circulation 113: e463-654. Link: https://bit.ly/3kohzbl

30. Desai N, Cortes A, Kita K, Rad N (2013) Young patients with acute myocardia infarction: How are thy different? JACC CV Interven 6: S9.

31. Dar MA, Mufti AA, Beshir Y, Khalaf H, Soomro TI, et al. (2013) ST elevation myocardial infarction in young adults: demographics, risk factor profile and early outcome after primary percutaneous coronary intervention. J Saudi Heart Assoc 25: 145. Link: https://bit.ly/2PyInYu

32. Mente A, Yusuf S, Islam S, McQueen MJ, Tanomsup S, et al. (2010). Metabolic syndrome and risk of acute myocardial infarction a case-control study of 26,903 subjects from 52 countries. J Am Coll Cardiol 55: 2390-2398. Link: https://bit.ly/3gwARsO

33. Harpaz D, Behar S, Rozenman Y, Boyko V, Gottlieb S, et al. (2003)

Citation: Sahi R, Shah R, Gajurel RM, Khanal RR, Poudel CM, et al. (2020) Cardiovascular risk factors and clinical pattern in young Nepalese population with acute coronary syndrome presenting to a tertiary care center of Nepal. J Cardiovasc Med Cardiol 7(3): 235-241.DOI: https://dx.doi.org/10.17352/2455-2976.000145 
Family history of coronary artery disease and prognosis after first acute myocardial infarction in a national survey. Cardiology 102: 140-146. Link: https://bit.ly/3a3GiwP

34. Harrap SB, Zammit KS, Wong ZYH, Williams FM, Bahlo M, et al. (2002) Genome-wide linkage analysis of the acute coronary syndrome suggests a locus on chromosome 2. Arterioscler Thromb Vasc Biol. Am Heart Assoc 22: 874-878. Link: https://bit.ly/31rl5ZX

35. Laudari S, Dhungel S, Dubey L, Panjiyar R, Gupta M, et al. (2017) Acute coronary syndrome in the young Nepalese popula on with their angiographic characteristics. Journal of College of Medical Sciences Nepal 13: 235-240. Link: https://bit.ly/31tsOqh

36. Tambyah PA, Lim YT, Choo MH (1996) Premature Myocardial Infarction in Singapore - Risk Factor Analysis and Clinical Features. 37: 31-33. Link: https://bit.ly/33NbShB

37. Colkesen AY, Acil T, Demircan S, Sezgin AT, Muderrisoglu H (2008) Coronary lesion type, location, and characteristics of acute ST elevation myocardial infarction in young adults under 35 years of age. Coronary Artery Dis 19: 345 347. Link: https://bit.ly/31px1eU
38. Alappatt N (2016) Acute coronary syndrome in young adults. Journal of Medical Sciences and Health 2.

39. Stone PH (1996) Prognostic significance of location of MI. American J of Cardiology 78: 19-25.

40. Sarr M, Ba DM, Ndiaye MB, Bodian M, Jobe M, et al. (2013) Acute coronary syndrome in young Sub- Saharan Africans: A prospective study of 21 cases. BMC Cardiovasc Disord13: 118. Link: https://bit.ly/3ilwBwV

41. Al-Khadra AH (2003) Clinical profile of young patients with acute myocardia infarction in Saudi Arabia. Int J Cardiol 91: 9-13. Link: https://bit.ly/30A4J1V

42. Kanitz MG, Giovannucci SJ, Jones JS, Mott M (1996) Myocardial infarction in young adults: Risk factors and clinical features. Emerg Med J 13: 139-145. Link: https://bit.ly/3gw4nyV

43. Magid DJ, Masoudi FA, Vinson DR, van der Vlugt TM, Padgett TG, et al. (2005) Older emergency departement patients with acute myocardial infarction receive lower quality of care than younger patients. Ann Emerg Med 13: 14-21. Link: https://bit.ly/3a29dS9
Discover a bigger Impact and Visibility of your article publication with Peertechz Publications

Copyright: (C) 2020 Sahi R, et al. This is an open-access article distributed under the terms of the Creative Commons Attribution License, which permits unrestricted use, distribution, and reproduction in any medium, provided the original author and source are credited.

Citation: Sahi R, Shah R, Gajurel RM, Khanal RR, Poudel CM, et al. (2020) Cardiovascular risk factors and clinical pattern in young Nepalese population with acute coronary syndrome presenting to a tertiary care center of Nepal. J Cardiovasc Med Cardiol 7(3): 235-241.DOI: https://dx.doi.org/10.17352/2455-2976.000145 